\title{
Renewable Polymerl Thermoplastics Polyethylene Blended with Enhanced Mechanical and UV Stability Properties
}

\author{
Nurul Syamimi M. Salim ${ }^{1, *}$, and M. Rus Anika Zafiah ${ }^{1}$ \\ ${ }^{1}$ Faculty of Mechanical and Manufacturing Engineering, University Tun Hussein Onn Malaysia \\ (UTHM), Parit Raja, 86400, Batu Pahat, Malaysia.
}

\begin{abstract}
Blends of Renewable Polymer (RP) and thermoplastic polyethylene (LDPE and HDPE) may contribute to make recycling more economically attractive. In this study, the monomer is mixed with flexible isocynate as a crosslinker, these mixture is called Renewable Polymer. Renewable polymers are mixed in a Low-density polyethylene (LDPE) and High-density polyethylene (HDPE) with a ratio of $5 \%, 10 \%, 15 \%, 20 \%$, $25 \%$ and $30 \%$. The aim of this work to make LDPE/RP and HDPE/RP blends injected via injection molding and to evaluate their mechanical properties via tensile test. Accelerated weathering test up for 500 hours, 1000 hours, 1500 hours, 2000 hours, 2500 hours and 3000 hours. The blends yielded tensile strength and maximum elongation at break curves very dependent on their composition, especially regarding the presence of necking. The tensile strength increase at 500 hours, while maximum elongation at break were found to decreased with increase of UV irradiation hours. In conclusion, RP content and UV irradiation time play significant roles in controlling mechanical properties of the RP-blended with LDPE and HDPE synthetic polymer, thus providing the opportunity to modulate polymer properties.
\end{abstract}

\section{Introduction}

As the economy achieves global status, many factors regarding the competitiveness of a nation come under investigation. More recently, together with important areas such as technology advancement and technology transfer, issues related to sustainable development and environment preservation are receiving increasing attention from the world community.

Advantages of the mechanical recycling of polymers include reduction of oil and energy consumption compared with the synthesis of virgin polymers, reduced disposal of plastic waste in municipal garbage and generation of employment and income. However, recycling of municipal plastic waste is often an arduous task due to the fact that is material is usually a mixture of several polymer, which makes processing more difficult and also limits the number of potential application [1].

\footnotetext{
${ }^{*}$ Corresponding author : nurulsyamimisalim@gmail.com
} 
The term of vegetable oils includes all vegetable oil such as olive oil, soybean oil, corn oil, coconut, palm oil and many others. The main constituents of vegetable oils are triacylglycerols, which are the product of esterification of glycerol with three fatty acids. Fatty acids account for $95 \%$ of the total weight of triglycerides and their content is characteristic for each vegetable oil [2]. In polymer industry, waste vegetable oils which represent a major potential source of chemicals have been utilized as an alternative feedstock for sustainable monomers.

Polyethylene (PE) is widely used material in outdoor applications, so its life time is determined by various environmental factors as solar radiation, temperature, thermal cycling, humidity, weather, pollutants but most importantly by ultra-violet (UV) radiation [3]. LDPE offer resistance to stress cracking and excellent impact properties, while HDPE provides stiffness, chemical resistance and barrier properties.

In this study, the evaluation of tensile properties of LDPE/RP and HDPE/RP blends was carried out to investigate the composition range for better mechanical performance and also to define the impact of UV irradiated exposure.

\section{Experimental}

Low density polyethylene $(\mathrm{LDPE})$ density $=0.922 \mathrm{~g} / \mathrm{cm} 3$, (melt index $=5 \mathrm{~g} / 10 \mathrm{~min}$, , vicat softening point $=93{ }^{\circ} \mathrm{C}$ ), high density polyethylene $(\mathrm{HDPE})$ density $=0.957 \mathrm{~g} / \mathrm{cm} 3$, (melt index $=4 \mathrm{~g} / 10 \mathrm{~min}$, vicat softening point $\left.=124^{\circ} \mathrm{C}\right)$, flexible Polymethane Polyphenyl Isocyanate (Modified polymeric-MDI) (viscosity at $25^{\circ} \mathrm{C}=120-160 \mathrm{cps}$, specific gravity at $25{ }^{\circ} \mathrm{C}=1.18-1.20 \mathrm{~g} / \mathrm{ml}$, NCO content, \% wt $\left.=26.3-27.3\right)$ and renewable monomers (renewable polyol). The monomer conversions from waste vegetable oils are started with their-house catalyst preparation to generate the epoxies from the unsaturated fatty compound. The acid-catalyst ring opening of the epoxides is to form renewable polyols.

Sample have been prepared in the form of dog-bone by injecting melted LDPE/RP and HDPE/RP in a mold as indicated in the ISO 527-2 (5A) standard. The injection machine is Nissei Horizontal Screw Type Injection Molding NP7 whose operating conditions were: temperature in nozzle $=185^{\circ} \mathrm{C}(\mathrm{LDPE}), 205^{\circ} \mathrm{C}(\mathrm{HDPE})$, temperature of first cylinder $=$ $175^{\circ} \mathrm{C}$ (LDPE), $180{ }^{\circ} \mathrm{C}$ (HDPE), temperature of second cyclinder $=165{ }^{\circ} \mathrm{C}$ (LDPE and HDPE), injection pressure = 43.3 MPa (LDPE), 96.6 MPa (HDPE).

Artificial aging undergone by sample was carried out in an accelerated wheatherometer. This type of testing uses UV irradiation simulating the solar irradiation while the other environmental parameters, such as temperature and relative humidity remain under control $\left(35-40{ }^{\circ} \mathrm{C}\right.$ and $50 \%$ respectively).The UV machine used is Haida International Equipment Co., LTD and is equipped with a UV Lamp Tested Model HD-703. Samples were radiated over variable times of 500, 1000, 1500, 2000, 2500 and 3000 hours.

Tensile test have been carried out to determine the evolution of tensile strength and percentage of breaking deformation versus percentage of renewable polymer. To this purpose, the ISO 527-2 (5A) has been applied using a Universal Tensile Machine AG-I, Shimadzu. Testing speed was $5 \mathrm{~mm} / \mathrm{min}$ and the load was $10 \mathrm{kN}$.

\section{Result and Discussion}

\subsection{Mechanical Properties of LDPE/RP blends after UV irradiation exposure.}

Figure 1 shows the trend of change for tensile strength of LDPE with blended of RP under UV irradiation exposure by UV wheatherometer. It showed in pure LDPE there's decreased 
in strength when under UV irradiation exposed but the decreasing is not lower than strength value of pure LDPE without UV irradiation exposed. With the addition of RP blends, it is observed that for LB5 and LB10, the initial 500 hours the tensile strength is increased from without UV irradiation exposed until 3000 hours. Meanwhile, for LB15 showed increasing tensile strength from without UV irradiation exposed to 500 hours until 1500 hours. At 2000 hours the strength decreased slightly until 3000 hours. It can be observed that LB20 and LB25 showed a similarity trends with increasing in tensile strength from without UV irradiation exposed to 500 hours and declined in tensile strength at 1000 hours to 3000 hours. For LB30, the tensile strength increased upon UV irradiation exposure from 500 hours until 1000 hours. When at 1500 hours it showed decreased strength until 3000 hours. On the one hand, upon UV irradiation exposed for each hour from 500 hours until 3000 hour the tensile strength decreased with addition of RP blends.

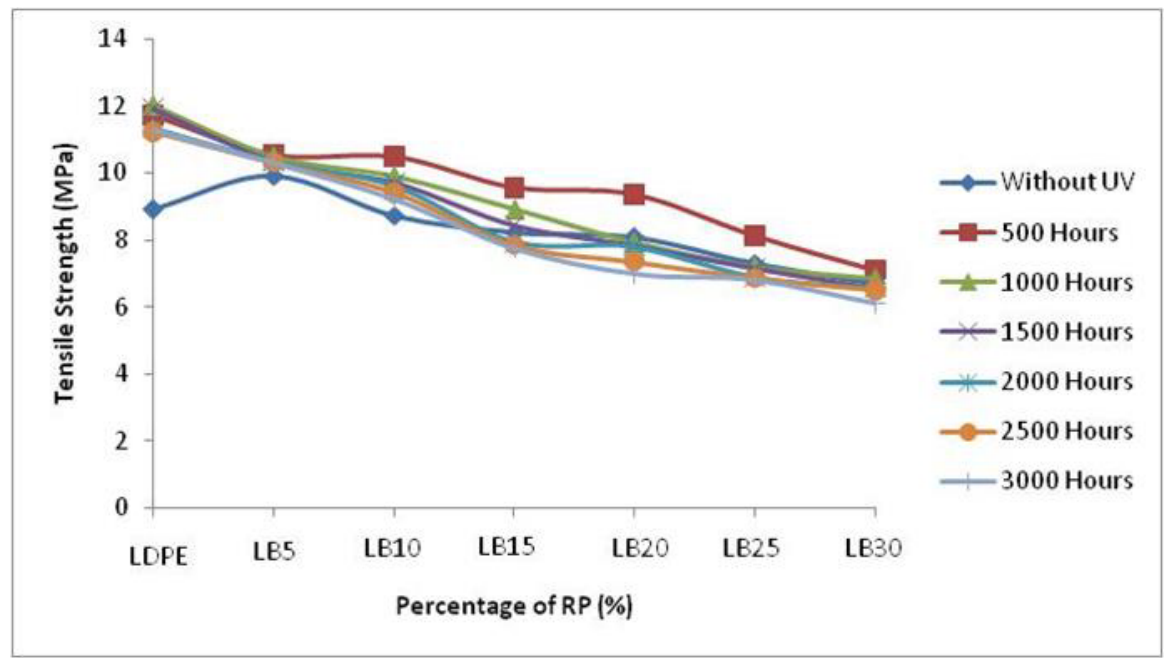

Fig. 1. Tensile Strength of LDPE/RP blends after UV irradiation Exposure.

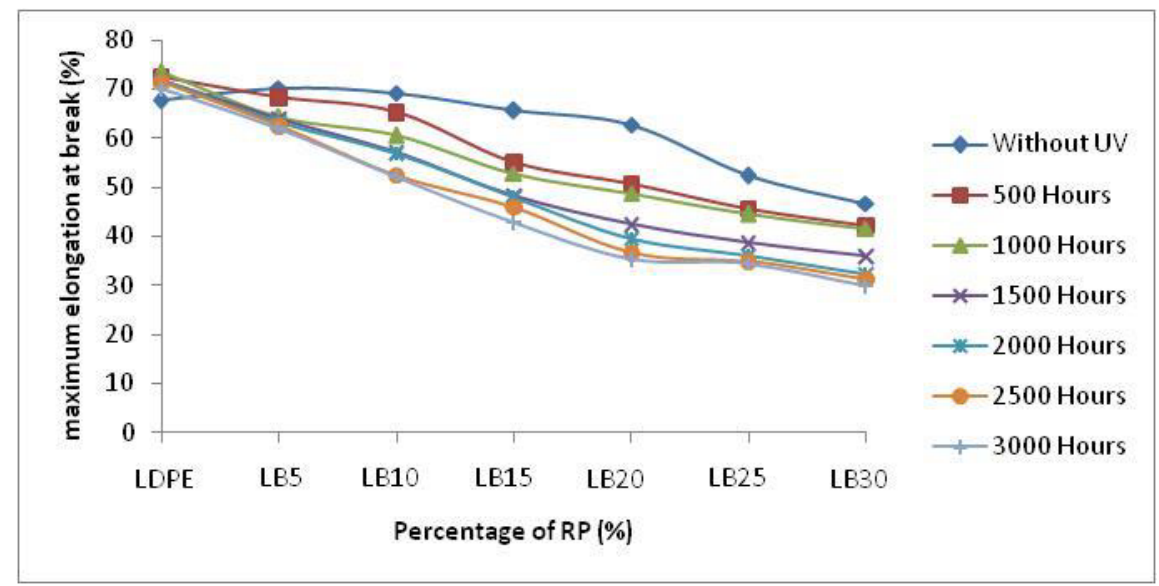

Fig. 2. Maximum elongation at break of LDPE/RP blends after UV irradiation Exposure. 
Figure 2 shows a graph of the percentage of maximum elongation with ultraviolet exposure time for each percentage of LDPE/RP blends. The graph pattern changes also decreased and increased in the percentage of maximum elongation. It is observed that the percentage of maximum elongation at break decrease with addition of RP under UV irradiation exposed. The increased of percentage maximum elongation at break of pure LDPE when under UV irradiation from 500 hours. For LB5, the percentage of maximum elongation at break decreased when under UV irradiation. It is showed same trends in LB10 until LB30. When UV irradiation exposed it showed decreased in percentage of maximum elongation at break with addition of RP. It gave same trends from 500 hours until 3000 hours.

Increasing the strength is likely by the reaction cross connection (crosslink) in the polymer chain as a result of exposure to ultraviolet. Previous studies also noted that the disclosure of ultraviolet is one method of crosslinking the polymer polyethylene [4]. The decline in tensile strength at the time of exposure may be due to the occurrence of the chain breaking process (chain scission) as a result of photo-oxidation. These include energy intensity and ultraviolet, foreign objects, particle size and free radicals formed during the synthesis of specimen processing [5].

\subsection{Mechanical Properties HDPE/RP blends after UV irradiation Exposure.}

For the variation of the tensile strength upon UV irradiation exposure, we can see that the tensile strength increasing under UV irradiation for pure HDPE. It observed from Figure 3 that for HB5, the tensile strength increased at initial 500 hours until 1000 hours and decreased at 1500 hours until 3000 hours. These trends have similar to HB10 and HB25. However, for HB15 the tensile strength increased upon UV irradiation exposed at 500 hour until 2000 hours. There were decreases in the value of tensile strength after 2500 hours of UV irradiation till 3000 hours of irradiation. Other than that, for HB20 and HB30 had same trends of increased in tensile strength at 500 hours until 1500 hours and then declined at 2000 hours until 3000 hours. This result was similar as found in the previous study which stated that tensile strength at yield point is remaining stable or increased slightly till 100 hours of UV radiation and after that time a gradual reduction took place in all samples [5]. Meanwhile, for each UV irradiation hours from 500 hours until 3000 hours showed decreased with the addition of RP.

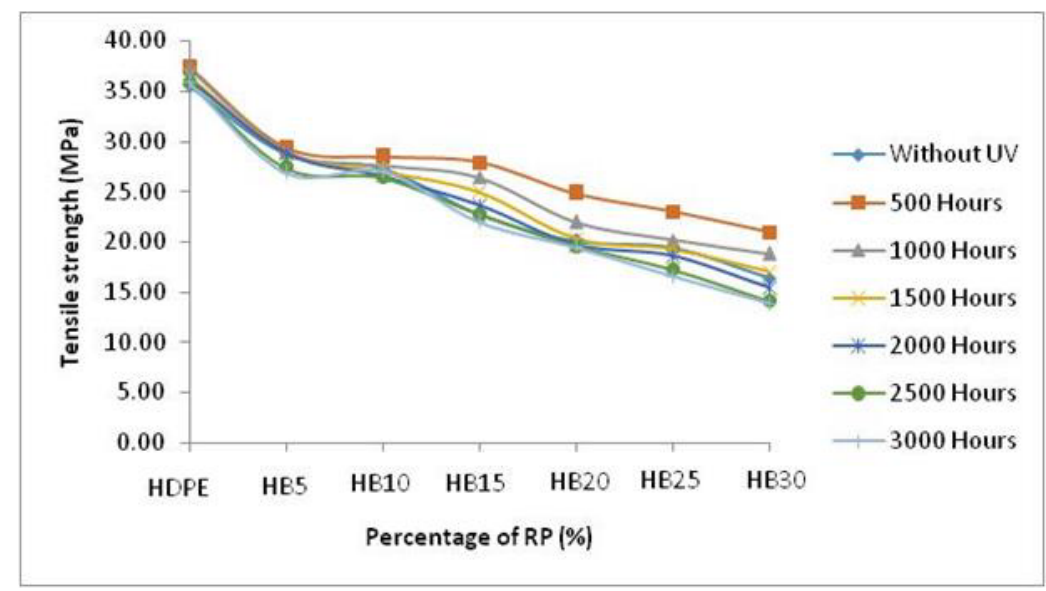

Fig. 3. Tensile Strength of HDPE/BP blends after UV irradiation Exposure. 


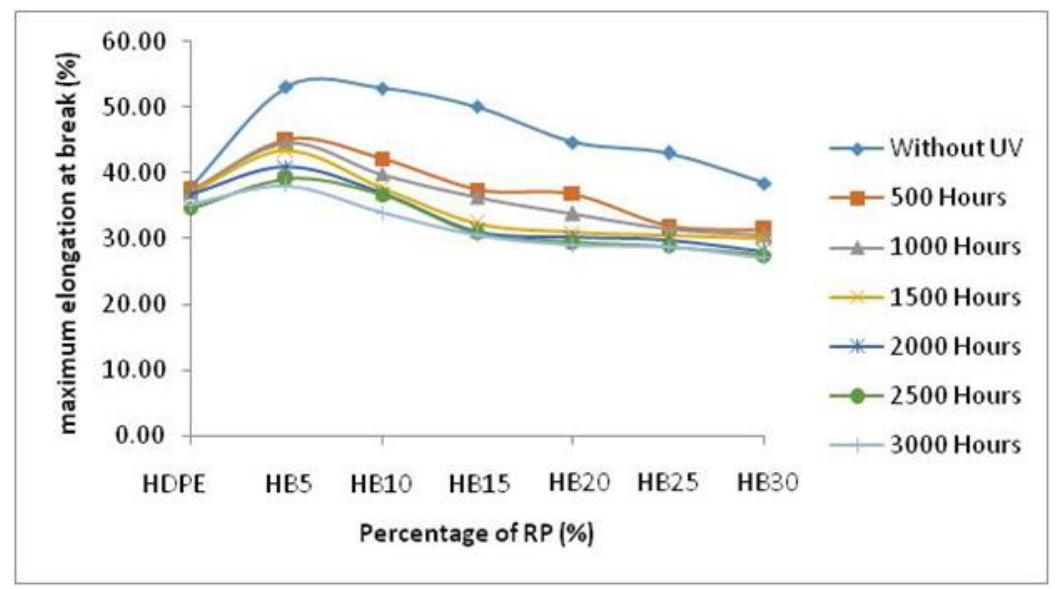

Fig. 4. Maximum elongation at break of HDPE/RP blends after UV irradiation Exposure.

With the UV irradiation there increased in percentage of maximum elongation at break with addition hours of UV irradiation exposed at pure HDPE as shown in Figure 4. For 500 hours, the percentage of maximum elongation at break increased at HB5, HB10 and HB15 and decreased at HB20, HB25 and HB30. At 1000 hours until 2000 hours, these trends similar that showed increased in percentage of maximum elongation at break at HB5 and HB10. However, it decreased in percentage of maximum elongation with addition of BP at HB15, HB20, HB25 and HB30. For 3000 hours, only HB5 increased in percentage of maximum elongation at break and then decreased at HB 10, HB15, HB20, HB25 and HB30. On the other hand, the percentage of maximum elongation at break decreased with addition of UV irradiation time for each addition of BP blends.

Based on previous study, during UV irradiation macromolecular chain scission is taking place that reduces the molecular weight of the polyethylene [7]. However, beyond chain scission, crosslinking reactions are, also, taking place simultaneously [6]. Crosslinking and accompanying stiffening may compete against chain scission and the resultant loss in molecular weight [8]. Thus, crosslinked macromolecules could increase initially the stiffness of HDPE while after a certain time a substantial reduction is caused to the HDPE molecular weight, due to chain scission reactions, reducing therefore its mechanical properties [6].

\section{Conclusion}

The renewable polymer (RP) was successfully blended with thermoplastic polyethylenes which are LDPE/RP and HDPE/RP and utilizing some modification processes like, UV irradiation. The overall process provides the freedom to develop a large variety of polymers with various mechanical properties. The characterization results indicate that the variations of renewable polymer (RP) content and UV irradiation are effective means to modulate the polymer's mechanical properties. The polymer strength decreased with the increase of renewable polymer (RP) content, while ductility of the polymer increased with the increase of the RP content. The UV irradiation of the polymer was enhanced with the increase of RP content. In conclusion, the renewable polymer/thermoplastic blended properties could be modulated by manipulating the RP content and UV irradiation exposure. 
The author would like to thank the Malaysian Government and University Tun Hussein Onn Malaysia (UTHM), Johor and Postgraduate Incentive Research Grant (GIPS) Vot U222.

\section{References}

1. R. Strapasson, S.C. Amico, M.F.R. Pereire, T.H.D. Sydenstricker, Polym. Test, 24, 468 (2005)

2. M.D.E. Lucas, M.A.R. Meier, Eur. Polym. J., 47(5), 837 (2010)

3. I.A. Husein, Polym. Degrad. Stabil, 92(11), 2026 (2007)

4. S.M. Tamboli, S.T. Mhaske, D.D. Kale, Indian Journal of Chemical Techonology, 11(6), 853 (2004)

5. M.A. Salem, Egypt J. Sol., 24(2), 141 (2001)

6. I. Grigoriadou, Compos. Part B-Eng., 55, 407 (2013)

7. J.L.S. Angulo, H.O. Ortega, S.S. Valdes, J. Appl. Polym. Sci., 53(7), 847 (1994)

8. J. Khan, S. Hamid, J. Polym. Mater., 15(2), 177 (1998) 